\title{
Precombustion Decarbonisation Processes
}

\author{
L.I. Eide ${ }^{1}$ and D.W. Bailey ${ }^{2}$ \\ 1 Hydro Oil \& Energy, N-0246 Oslo - Norway \\ 2 Alstom Power Turbo-Systems Technology Centre, Cambridge Road, Whetstone Leicester, LE8 6LH - United Kingdom \\ e-mail: lars.ingolf.eide@hydro.com
}

Résumé - Capture précombustion - Dans le cas de la capture par précombustion, le $\mathrm{CO}_{2}$ est isolé avant la combustion. Cette technologie mature et bien maîtrisée, s'apparente à la production d'hydrogène. Ses performances sur des combustibles gaz naturel et charbon sont ici présentées. Ce procédé se déroule en trois étapes :

- obtention d'un mélange contenant de l'hydrogène, du $\mathrm{CO}$ et du $\mathrm{CO}_{2}$ à partir de réactions de reforming/conversion du combustible ;

- obtention d'un mélange contenant du $\mathrm{CO}_{2}$ et de l'hydrogène ;

- séparation du $\mathrm{CO}_{2}$ et de l'hydrogène.

Il existe quelques pistes de développement de cette technologie, tel le IRCC (Integrated Reforming Combined Cycle).

\footnotetext{
Abstract - Precombustion Decarbonisation Processes - In precombustion decarbonisation, the $\mathrm{CO}_{2}$ is captured before burning the fuel. The method has many parallels to the method of producing hydrogen which is a mature technology. Technology performances are given for gas-based and coal-based processes. The technology comprises three steps:

- reforming/conversion of fossil fuel to a mixture containing hydrogen, $\mathrm{CO}_{2}$ and $\mathrm{CO}$;

- shifting this mixture to a mixture with $\mathrm{CO}_{2}$ and $\mathrm{H}_{2}$;

- separation of $\mathrm{CO}_{2}$ and hydrogen.

There are a few development options, like the IRCC (Integrated Reforming Combined Cycle).
} 


\section{BASIC PROCESS AND ENERGY CONVERSION DESCRIPTION}

Precombustion decarbonisation (PrCDC) is a method to capture carbon in the form of $\mathrm{CO}_{2}$ from fossil fuels before burning the fuel in a combustor. The method has many parallels to the method of producing hydrogen and is in some cases simply designated hydrogen production (with $\mathrm{CO}_{2}$ removal). The basic steps in technology have been used for more than 50 years and are considered to be mature, with little potential for improvements, but for PrCDC, the design requirement changes. Hydrogen is generally produced at high purity for chemical, refining and other uses. For PrCDC one can relax this requirement and cost reduction can be expected. As PrCDC is a new application, the concept needs to be adopted by the technology providers before improvements can be expected.

\subsection{Gas Based Processes}

The main reactions for converting a methane rich fuel into a hydrogen rich fuel are:

- Steam reforming: $\mathrm{CH}_{4}+\mathrm{H}_{2} \mathrm{O}<->\mathrm{CO}+3 \mathrm{H}_{2}$ $+206.2 \mathrm{MJ} / \mathrm{kmol} \mathrm{CH}_{4}$

- Partial oxidation: $\mathrm{CH}_{4}+1 / 2 \mathrm{O}_{2}<->\mathrm{CO}+2 \mathrm{H}_{2}$ - $35.7 \mathrm{MJ} / \mathrm{kmol} \mathrm{CH}_{4}$

- Water gas shift: $\mathrm{CO}+\mathrm{H}_{2} \mathrm{O}<->\mathrm{CO}_{2}+\mathrm{H}_{2}$ $-41 \mathrm{MJ} / \mathrm{kmol} \mathrm{CH}_{4}$

Several technologies for gas reforming exist:

- Conventional steam methane reforming (SMR), in which the main reaction is steam reforming, which takes place in long catalyst filled reformer tubes. Heat for the highly endothermic reaction is provided by burning fuel gas.

- Heat exchange reformer (HER)/gas heated reformer (GHR), in which the main reaction is steam reforming, for which the endothermic reforming heat is provided from a hot gas stream passing through the reformer.

- Pressurized combustion reforming, which is a special case of a heat exchanger reformer where the hot gas is produced by burning a fraction of the $\mathrm{H}_{2}$ rich fuel gas at high pressure

- (Non-catalytic) partial oxidation (POX), in which the main reaction is partial oxidation. Natural gas is mixed with oxygen or air in a burner and partially oxidized at high temperature and high pressure to obtain reasonable reaction rates. The heat is mainly generated by the exothermic partial oxidation reaction.

- Catalytic partial oxidation (CPO), in which the main reaction is partial oxidation. A mixture of natural gas and an oxidant can be ignited on the surface of a noble metal catalyst (e.g. rhodium or palladium). The extremely high reaction rates allow very short residence times. This technology is not commercially available for large scale applications today.

- Autothermal reforming (ATR), in which there are two main reactions: partial oxidation and steam reforming. Natural gas is mixed with oxygen, or air, and steam in a mixer/burner. In the combustion chamber partial combustion reactions are taking place, followed by methane steam reforming reaction and shift conversion to equilibrium over the catalyst bed. The overall reaction is exothermic, resulting in a high outlet temperature, typically 850$1000^{\circ} \mathrm{C}$.

(There is sometimes an interchange of terms for what is above described as CPO and ATR).

Table 1 summarizes the features of the reforming technologies available today.

In addition to the reformer technology choices described above, the installation of a catalytic prereformer, operating at approximately $500^{\circ} \mathrm{C}$, can be considered to increase the overall fuel conversion efficiency. A prereformer converts most

TABLE 1

Features of commercially available reforming technologies

\begin{tabular}{c|c|c|c}
\hline & Steam reforming & Partial oxidation & Autothermal reforming \\
\hline Abreviation & $\mathrm{SMR}$ & POX & ATR, CPO \\
\hline Catalyst & $\mathrm{Ni}$ & - & $\begin{array}{c}\text { Partial oxidation: }- \\
\text { Steam refroming: Ni }\end{array}$ \\
\hline Pressure & $15-40 \mathrm{bar}$ & $->150$ bar & $20-40 \mathrm{bar}$ \\
\hline Temperature & $750-900^{\circ} \mathrm{C}$ & $1200-1600^{\circ} \mathrm{C}$ & $850-1100^{\circ} \mathrm{C}$ \\
\hline Reaction & $\mathrm{CH}_{4}+\mathrm{H}_{2} \mathrm{O}<->\mathrm{CO}+3 \mathrm{H}_{2}$ & $\mathrm{CH}_{4}+1 / 2 \mathrm{O}_{2}<->\mathrm{CO}+2 \mathrm{H}_{2}$ & $\begin{array}{c}\mathrm{CH}_{4}+1 / 2 \mathrm{O}_{2}<->\mathrm{CO}^{2}+2 \mathrm{H}_{2} \\
\mathrm{CH}_{4}+\mathrm{H}_{2} \mathrm{O}<->\mathrm{CO}_{3} 3 \mathrm{H}_{2}\end{array}$ \\
\hline Enthalpy & $+206.2 \mathrm{MHJ} / \mathrm{kmol} \mathrm{CH} 4$ & $-35.7 \mathrm{MHJ} / \mathrm{kmol} \mathrm{CH} 4$ & Exothermic \\
\hline $\mathrm{H}_{2} / \mathrm{CO}$ ratio & $3-6$ & 1.8 & $1.8-3.7$ \\
\hline
\end{tabular}


of the heavier hydrocarbons while the main reformer unit preferably converts methane to $\mathrm{CO}$ and $\mathrm{H}_{2}$.

Precombustion decarbonisation operates with two types of plant definitions:

- the non-integrated stand-alone PrCDC plant;

- the integrated PrCDC/power plant.

The non-integrated PrCDC plant covers the general case where the fuel preparation and fuel users are completely separate. Produced hydrogen can be piped to fuel users such as steam boilers, refineries, distributed gas turbines, etc. The integrated PrCDC/power plant covers the Integrated Reforming Combined Cycle (IRCC) where examples are HydroKraft (Norsk Hydro concept). Here air and fuel systems are integrated across the turbine, the fuel processor and the heat recovery/steam generation units. The latter is described in Section 4.

\subsection{Solid Fuel Based Processes}

Coal is guaranteed to be a major part of the electricity mix for many years to come because of its abundance; it is distributed world-wide, but especially present in the developing countries. However, with many coals being high in sulphur and tighter emissions regulations being set, along with carbon dioxide capture being considered for emissions control, the need is there for a clean coal technology such as IGCC (Integrated Gasification Combined Cycle).
An IGCC system consists of a gasifier (perhaps including an air separation unit), a gas clean up system and a combined cycle power island (Fig. 1). IGCC is thought to have significant potential in markets where natural gas prices are rising and environmental legislation is tightening. However, there is still some concern at the relatively high capital costs, the high operation and maintenance $(\mathrm{O} \& \mathrm{M})$ costs, the long time required to start the plant and the low availability of IGCC plant.

Gasification or partial oxidation of solid carbonaceous feed stocks produces a fuel gas which can be cleaned and burnt in a gas turbine. The fuel gas must be of such a quality that no corrosion or erosion is caused to the gas turbine (GT), whilst maintaining the high efficiency and low emissions of the combined cycle plant. Current gasification technology can conserve $80-90 \%$ of the chemical combustion energy in the feedstock material. The fuel gas produced by gasification is cleaned so that solids, such as ash, cannot pass through a GT as they lead to erosion. Alkali metals are also removed as in combination with sulphur because they can lead to severe corrosion.

A key aspect in gasification systems is whether the gasifying agent is oxygen or air. Oxygen blown gasifiers produce syngas with a higher calorific value, as the gas is not exposed to the diluent effect of nitrogen in the air. Furthermore, the size of all of the downstream components can be smaller as the volume of nitrogen is not present. However the oxygen blown system does require an air separation unit, which is a costly and complex piece of equipment.

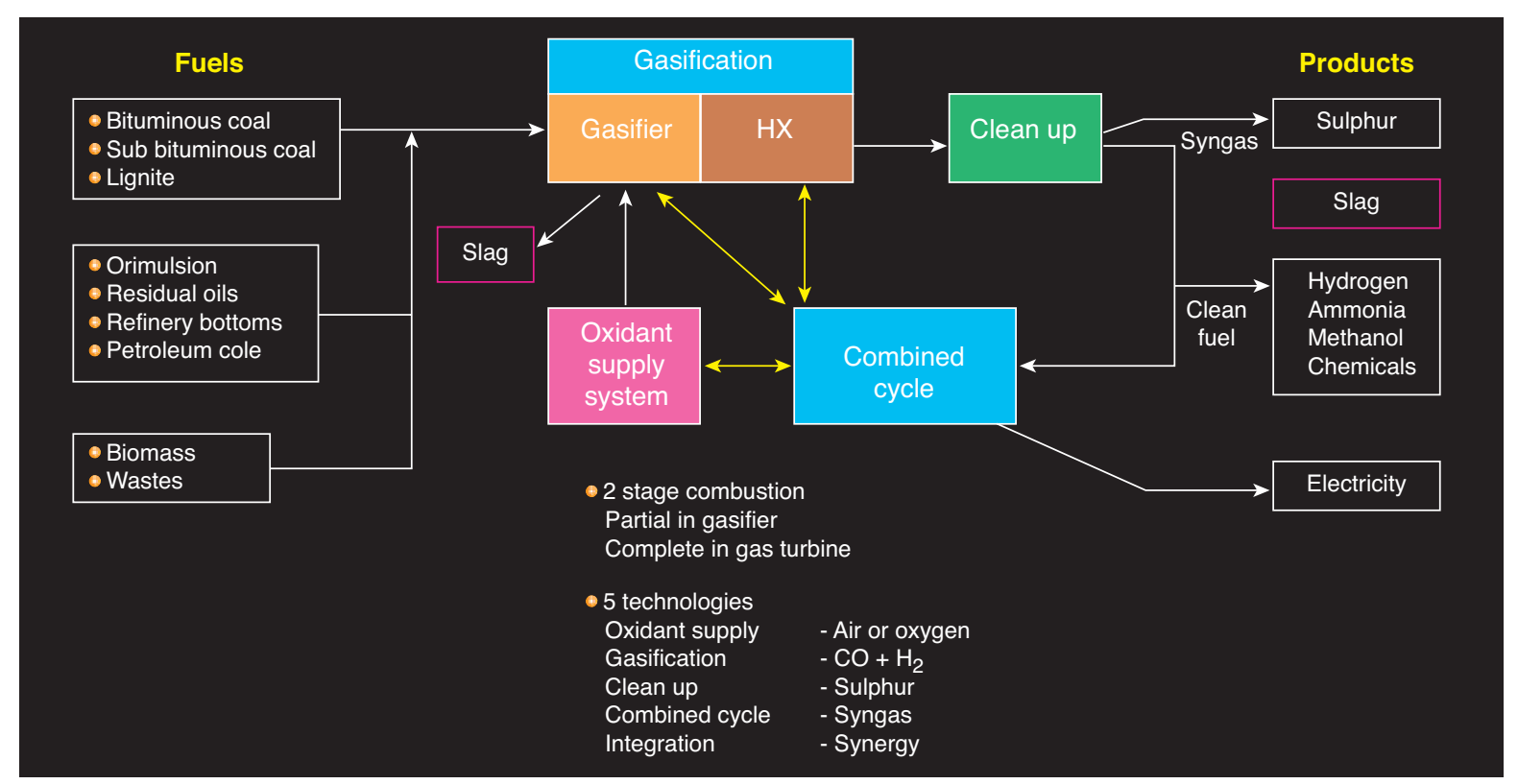

Figure 1

Schematic of integrated gasification combined cycle. (Brun and Jones, 2001). 

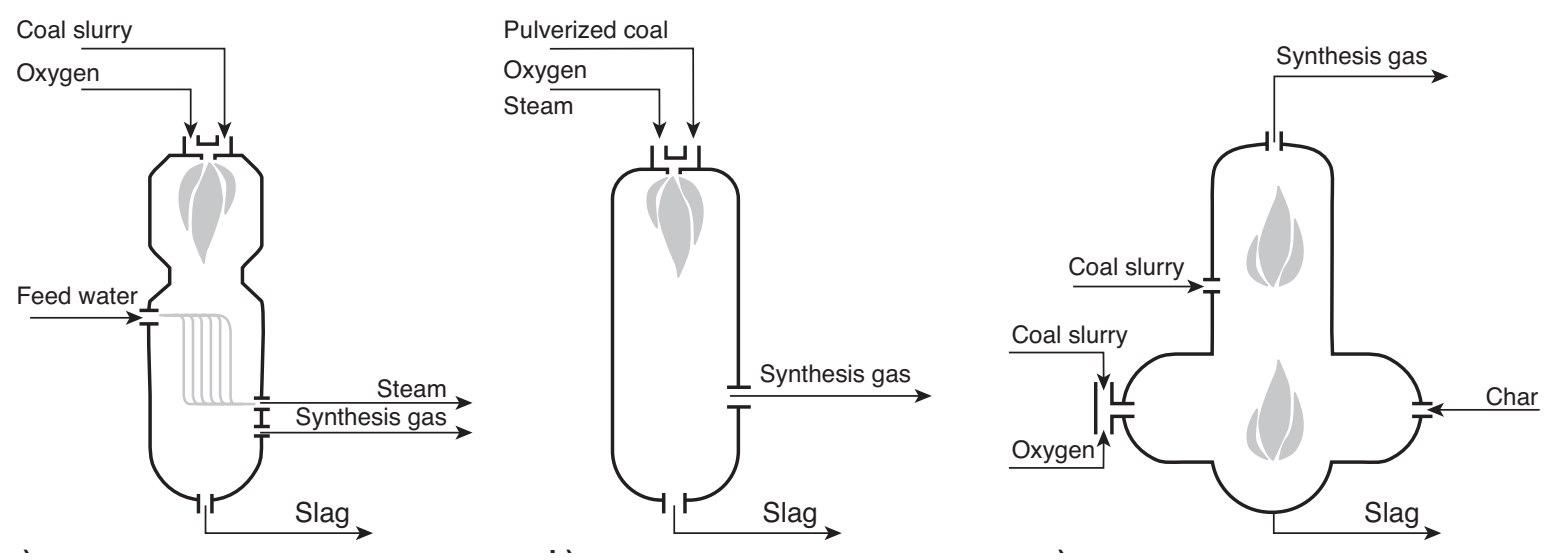

Figure 2

Schematic of entrained flow gasifiers. a) Chevron Texaco; b) Shell; c) E-GAS).

The most popular choice of gasifier for refinery residue and coal gasification has been the entrained flow gasifier (Fig. 2).

For the entrained flow gasifier, the fuel flows concurrently with the oxidising agent and steam, they are characterised by very high temperatures $\left(1200-1600^{\circ} \mathrm{C}\right)$, and short residence times of a few seconds.

The Chevron Texaco entrained flow gasifier (Fig. 2a) is a single stage downward firing system, in which the fuel slurry (30-40\% water) and oxygen are injected into the top of the gasifier. The water content of the slurry replaces most of the steam that would normally be added into the system. At high temperatures the fuel reacts with the oxygen to form syngas and molten ash. The hot gas flows downward to the syngas cooler where high-pressure steam is produced. The cooled syngas passes over the surface of a pool of water at the bottom of the cooler and exits the vessel. The slag drops into the pool and is removed from the bottom of the vessel. The water exiting with the slag is then separated and recycled. The Chevron Texaco Corporation's gasification technology business is now part of General Electric's energy division.

The Shell entrained flow gasifier (Fig. 2b) is a carbon steel vessel which contains a gasification chamber, enclosed by a non-refractory membrane wall. Water is circulated through the membrane wall to control the wall temperature and raise steam. The fuel is pulverised, dried and pressurised before entering the gasifier. Fuel oxygen and steam are injected into the gasifier, which operates at pressures from 2-4 $\mathrm{MPa}$ and temperatures above $1500^{\circ} \mathrm{C}$. This high temperature ensures that the ash melts and is allowed to run freely down the membrane wall to a water filled container at the bottom of the gasifier where it solidifies and is removed. Some of the molten slag collects on the cooled membrane walls and forms a protective coating. The crude raw syngas is quenched at the gasifier exit by cooled recycled product gas and is then further cooled in a syngas cooler raising steam. It is then filtered using ceramic filters.

The E-GAS entrained flow gasifier (Fig. 2c) is a two stage gasifier, where approximately $80 \%$ of the total slurry feed is fed to the first (bottom) stage of the gasifier along with oxygen. The fuel is partially combusted at temperatures of $1350-$ $1400^{\circ} \mathrm{C}$ and a pressure of $3 \mathrm{MPa}$. The molten ash that is formed flows down the gasifier through a tap hole and into a water quench. The fuel gas produced in the lower stage then flows upwards into the second stage where the remaining $20 \%$ of the fuel slurry is injected into the hot raw gas. The endothermic gasification reactions in this stage reduce the temperature of the final product gas as well as introducing some hydrocarbons into the gas thereby increasing its calorific value. Char is produced in the second stage and is recycled to the hotter first stage where it is readily gasified. The crude product gas is cooled in a syngas firetube cooler. The E-GAS gasifier is a boiler system, with the hot gas circulating on the boiler side. This is thought to be more economic than the cooling systems used by Shell and Chevron Texaco where the water circulates in tubes in a syngas tank.

There is a wide variety of gasifiers in development including;

- fluidised bed gasifiers (KRW, Foster Wheeler);

- transport reactor gasifiers (Kellog);

- Moving bed gasifiers (Lurgi, British Gas).

However, in the refinery residue and coal market $75 \%$ of gasifiers have been of the entrained flow variety. This is because the entrained flow gasifiers have a very short gas residence time of only a few seconds which allows a very high load capacity and therefore is well suited to large-scale applications where the volume of fuel to be handled is high. Furthermore, the entrained flow gasifiers in use produce a slag as a waste product. This slag has a market value as a construction material as it is not hazardous waste. All of the 
entrained flow gasifiers currently in operation or construction are of the oxygen blown variety producing medium calorific gas. This type of system is desirable in a refinery residue application, as it is possible to produce hydrogen from the syngas more easily than with an air blown system. The market leaders in the gasification of refinery residues and coal are Shell and Texaco, with both of these manufacturers operating large-scale commercially successful units with refinery residues.

\section{STATE-OF-THE-ART}

\subsection{Introduction}

Precombustion decarbonisation technology is today in commercial operation for different applications, e.g. hydrogen, ammonia and syngas production. The technology is based on well known technology components and comprises the two main steps described above-reforming/conversion of fossil fuel to a mixture containing hydrogen, $\mathrm{CO}_{2}$ and $\mathrm{CO}$ (syngas) and separation of $\mathrm{CO}_{2}$ and hydrogen to produce a hydrogen-rich stream.

Conversion of fossil fuel to syngas dates back to the Scottish engineer William Murdoch, who in 1792 used the gas to light up his house. The gas was later designated town gas or city gas. It was used worldwide between 1800 and 1920. Following coal gasification, the technology of reforming natural gas by use of catalyst was introduced in the late 30 's and is today the primary method to convert natural gas into syngas.

The development of reforming technologies for natural gas and similar went in two directions:

- steam methane reforming;

- autothermal reforming.

The improvement of steam methane reforming from the introduction in the 30's has been on increasing operating pressure and temperature by development of new catalyst and reactor materials.

The first system for producing hydrogen for ammonia by combining syngas production and separation of hydrogen and $\mathrm{CO}_{2}$ dates back to the 40 's, with low pressure steam reforming followed by compression to 15 bar and separation by $20 \%$ monoethanolamine (MEA) for $\mathrm{CO}_{2}$ separation. In the mid-50's, a technology using hot potassium carbonate was introduced as an alternative to the MEA process, and in the late 70's, activated methyldiethanolamine (MDEA) solvent was introduced leading to a significant improvement in energy efficiency.

More than $90 \%$ of today's production of hydrogen$500 \mathrm{Gm}^{3} / y$ according to IEA-is based on reforming of fossil fuel. This implies that about 500 reformers with an average capacity of $100000 \mathrm{Nm}^{3} / \mathrm{h}$ hydrogen are in operation worldwide.
Precombustion decarbonisation technology is complex involving a number of catalytic steps, heating to high temperatures and cooling to low temperatures. What might favour one part of the process might be a disadvantage for another part. As an example, reforming is favoured by low pressure, but separation of $\mathrm{CO}_{2}$ is favoured by high pressure. Also energy efficiency is favoured by low steam addition (also called steam to carbon ratio), but hydrogen production is favoured by high steam addition.

Some key items for PrCDC are (Thomas (ed.), 2004):

- PrCDC technology has been demonstrated in a large scale application at conditions required for $\mathrm{CO}_{2}$ capture and storage (CCS). This implies credibility with respect to efficiency, lifetime, $\mathrm{CO}_{2}$ capture, cost and operation.

- A large commercial market exist today for core pieces of the PrCDC technology and therefore cost advantages can be obtained in real life projects due to competition, between both technology licensors and main contractors.

- Precombustion technology generates a hydrogen-rich fuel, which can be used for other purposes, thus creating positive synergies.

- The increased focus on hydrogen and fuel cells in Europe, North-America and Japan will create a platform for new developments of reforming technology.

The technology is widely applicable within syngas production for methanol, synfuel, ammonia and hydrogen, etc. Thus technology improvements can be adopted as well in these areas. As an example, a large gas-to-liquid plant cost about $\$ 1 \mathrm{G}$ and $60 \%$ of the cost relates to the syngas technology.

Further, significant improvement in some of the technologies could enter the chain for future low cost hydrogen for hydrogen fuel cell vehicle. Hydrogen production with capture and storage of $\mathrm{CO}_{2}$ will "bridge-the-gap" towards the renewable hydrogen economy and make a more economical viable transition.

Some principles are widely accepted as state-of-the-art when applying technology for major process plant based on proprietary technology. These include the following three criteria:

- The technology providers have to give process guarantees without risk-sharing, showing the provider has confidence in the technology offered.

- The technology provider shall to some extent be able to provide references. This both supports point 1 but also gives the client confidence in the feasibility of the technology.

- International financing partners shall generally accept the technology. In most cases a financing partner is part of the owner team and therefore the technology expert on their side has to have confidence in the technology.

The consequence of the above listed set of criteria is that improvements operate in a very narrow frame and that the state-of-the-art moves very slowly for this type of technology. 
TABLE 2

Performances and costs for precombustion decarbonisation technology

\begin{tabular}{c|c|c|c}
\hline Technology & Performance, energy efficiency $(\%)$ & Plant type & $\mathrm{CO}_{2}$ Capture cost $(\$ / t)$ \\
\hline SMR & $66-75$ & Non-integrated & $70-85$ \\
\hline ATR & $65-83$ & Integrated and non-integrated & $40-70$ \\
\hline POX & $\begin{array}{c}\text { I3 - Gas feed } \\
60-\text { Coal feed }\end{array}$ & $40-80$ \\
\hline
\end{tabular}

This can be seen by the modest improvements made over the last 20-30 years within hydrogen technologies. For pre-combustion decarbonisation this implies that the best available technology or process steps from individual plants operating worldwide are selected and that they are combined into a state-of-the-art PrDC configuration.

\subsection{Performances and Costs}

Quality assurance of vendor data will be an important role for the technology teams and especially quality assurance of performance and cost data. For state-of-the-art PrCDC this should not cause considerable concern as most data are available in-house and can be cross-checked against vendor data at any time. Table 2 outlines cost and performance data for PrCDC technology.

As regards solid fuel based PrCDC the International Energy Agency (IEA) Greenhouse Gas R\&D Programme has performed an evaluation (Domenichini, 2003) of IGCC based on two oxygen blow entrained bed gasifiers:

- a Texaco slurry feed gasifier, with product gas cooling by water quench;

- a Shell dry-feed gasifier, with product gas cooling in a heat recovery boiler.

Both plants are based on the General Electric 9FA gas turbines which are representative of the current state-of-theart for large heavy duty gas turbines. Air separation is by a cryogenic unit with $50 \%$ of the air supplied at pressure by the gas turbine and the remaining 50\% supplied by a separate compressor. The plants have been based around a configuration of 2 gas turbines and 1 steam turbine which provides economies of scale and results in net power outputs of around $750 \mathrm{MW}$. The study was carried out by Foster Wheeler who obtained performance and cost data from process technology and equipment suppliers. Performances of the state-of-the-art IGCC plant are shown in Table 3.

\section{Suppliers and References}

It is expected that suppliers of hydrogen, ammonia and methanol technology are capable of providing state-of-the-art precombustion decarbonisation technology. Vendors are located both in the United States and Europe which gives
PrCDC a unique position in terms of competitiveness and selection for the different projects.

TABLE 3

Basic performance summary (Domenichini, 2003)

\begin{tabular}{l|c|c|c}
\hline & Units & $\begin{array}{c}\text { IGCC } \\
\text { (Shell dry } \\
\text { feed gasifier) }\end{array}$ & $\begin{array}{c}\text { IGCC } \\
\text { (Texaco slurry } \\
\text { feed gasifier) }\end{array}$ \\
\hline Generating capacity & $\mathrm{MW}$ & 776 & 826 \\
Power production & $\mathrm{MW} / \mathrm{y}$ & $5,778,096$ & $6,150,396$ \\
Efficiency (LHV) & $\%$ & 43.1 & 38.0 \\
Wet gas flow rate & $\mathrm{kg} / \mathrm{s}$ & 1490.0 & 1395.2 \\
NOx & $\mathrm{kg} / \mathrm{MWh}$ & 0.5845 & 0.4494 \\
SOx & $\mathrm{kg} / \mathrm{MWh}$ & 0.0365 & 0.0061 \\
Particulate matter & $\mathrm{kg} / \mathrm{MWh}$ & 0.0361 & 0.0304 \\
Carbon monoxide $(\mathrm{CO})$ & $\mathrm{kg} / \mathrm{MWh}$ & 0.2268 & 0.1883 \\
Carbon dioxide & $\mathrm{kg} / \mathrm{MWh}$ & 763 & 833 \\
\hline
\end{tabular}

The main references today are provided from the hydrogen and ammonia industry. Today ammonia plants are designed with capacities up to 2000 MTPD. The hydrogen produced in such a plant could provide fuel for a $300 \mathrm{MW}$ combined cycle. Further the captured $\mathrm{CO}_{2}$ is approximately 850 000-1 000000 MTPA. As $\mathrm{CO}_{2}$ in ammonia plants is used for urea production the $\mathrm{CO}_{2}$ is compressed to $160 \mathrm{bar}$ and sent to the urea plant. This gives valuable information about $\mathrm{CO}_{2}$ compression and transport. For hydrogen technology plant up to $140000 \mathrm{Nm}^{3} / \mathrm{h}$ exist which corresponds to $240 \mathrm{MW}$ in combined cycle power output.

\section{COMPONENT AND PROCESS CONSIDERATIONS}

\subsection{Technology Description}

In general a precombustion decarbonisation plant can be divided into three sections:

- hydrocarbons conversion;

- CO-conversion;

- $\mathrm{CO}_{2}$ removal;

This is illustrated in Figure 3. 


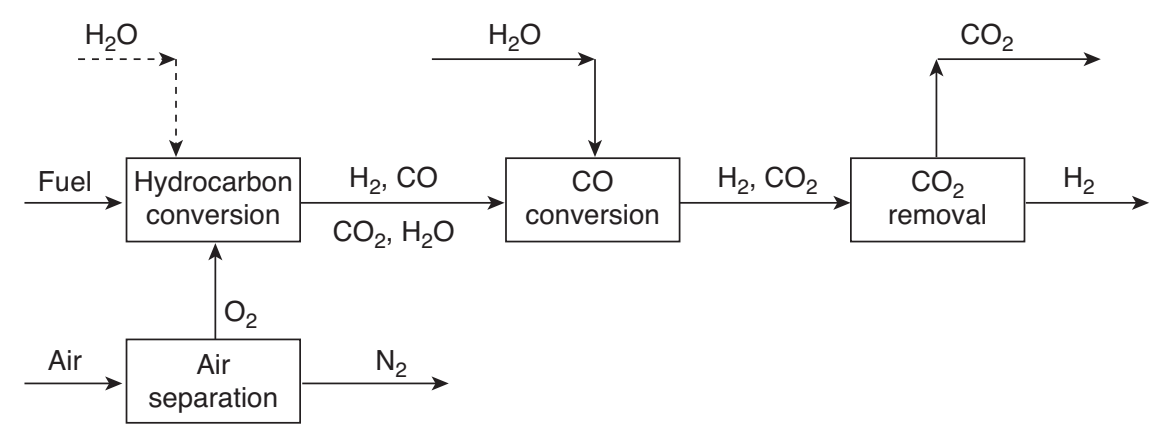

Figure 3

The basic sections of a precombustion decarbonisation process.

TABLE 4

Technologies for hydrocarbon conversion

\begin{tabular}{l|l|l|l}
\hline Technology & Description & Fuel type & Applications \\
SMR & Steam methane reforming & Natural gas, naphtha & Hydrogen, ammonia \\
ATR & Autothermal reforming & Natural gas & Ammonia, GTL \\
POX & Partial oxidation & All types & IGCC, ammonia, GTL \\
SMR+ATR & Two-step reforming & Natural gas, naphtha & Ammonia, methanol \\
\hline
\end{tabular}

\subsection{Hydrocarbon Conversion}

The objective of hydrocarbon conversion is to convert hydrocarbon into $\mathrm{H}_{2}, \mathrm{CO}$ and $\mathrm{CO}_{2}$. This is normally done by steam reforming, partial oxidation or a combination of both. The technology selection mainly depends on the feed stock type. Table 4 gives the applied technology and type of feed stock.

The choices of oxidants are air, oxygen, and oxygenenriched air. The advantage of using oxygen or oxygenenriched air is the reduced amount of inert gas, mainly $\mathrm{N}_{2}$, which may potentially reduce equipment size. However, in most cases additional steam is required to avoid excessive temperatures in the reformer and $\mathrm{CO}$ converter. In addition, the high electricity consumption of an air separation unit (ASU) reduces the thermal efficiency and thus increases the operating costs due to increased natural gas consumption.

\subsection{CO-Conversion}

CO-conversion is the step in which the $\mathrm{CO}$ generated in the hydrocarbon conversion section is converted into hydrogen and $\mathrm{CO}_{2}$ by water gas shift reaction. The predominant method is a two-step approach in which the major conversion takes place at high temperature called high temperature shift (HTS) and final conversion takes place at low temperature called low temperature shift (LTS). Other system using medium temperature shift (MTS) and improved reactor design exist. The shift systems are normally found in hydrogen and ammonia plants.

The choice of technologies available to perform the $\mathrm{CO}$ conversion is limited. The major difference between the various schemes is the number of units and the temperature levels they are operated at:

- high temperature (HT) shift, typically operated at $350^{\circ} \mathrm{C}$;

- medium temperature (MT) shift, typically operated at $250-300^{\circ} \mathrm{C}$;

- low temperature (LT) shift. Typically operated at 190$210^{\circ} \mathrm{C}$.

The main choice is between two adiabatic $\mathrm{CO}$ converters (HT and LT) or a single approximately isothermal MT shift reactor.

The overall $\mathrm{CO}_{2}$ capture rate is determined by the fuel conversion efficiency of the reformer and shift reactor, which will not be as high as the capture efficiency of the $\mathrm{CO}_{2}$ removal unit, because unconverted hydrocarbons and $\mathrm{CO}$ will form $\mathrm{CO}_{2}$ in the gas turbine. Rejected $\mathrm{CO}_{2}$ from the $\mathrm{CO}_{2}$ removal unit will pass through the gas turbine. In the case where the product of the fuel conversion and $\mathrm{CO}_{2}$ removal efficiency are higher than the given target, natural gas can be chosen to bypass the front-end and enter the combustion section of the gas turbine directly. This way the thermal efficiency can be improved while the specified overall carbon capture target is met. However, exceeding the carbon capture target is in these cases feasible and does in most cases not increase the specific cost of $\mathrm{CO}_{2}$ avoided. 


\section{$3.4 \mathrm{CO}_{2}$ Removal}

After the CO-conversion and removal of process condensate, the process gas mainly consists of hydrogen and carbon dioxide. If air has been used as oxidant in the ATR or POX large amounts of nitrogen will be present. Traces of unconverted $\mathrm{CO}$ and methane will also be present.

Several technologies exist to remove $\mathrm{CO}_{2}$ from a gas stream, see the chapter on post-combustion. Some often considered ones are:

- Pressure swing adsorption (PSA), which is suitable for pure hydrogen applications but with the syngas compositions usually obtained, the hydrogen losses would be unacceptable.

- Cryogenic separation, in which $\mathrm{CO}_{2}$ is physically separated from the syngas by condensing it at cryogenic temperatures to produce liquid $\mathrm{CO}_{2}$ ready for storage. Cooling the entire syngas stream would consume large amounts of electricity and is therefore unattractive.

- Chemical absorption, which uses an activated monodiethanolamine (MDEA) solution. This process is often referred to as amine scrubbing and the most commonly applied $\mathrm{CO}_{2}$ removal technology today.

- Physical absorption using Selexol or Rectisol (cold methanol) is advantageous at high $\mathrm{CO}_{2}$ partial pressure and is thus very suitable for products from gasification.

- Membrane separation is commercially applied for hydrogen separation, but more development is required before membranes can be used on a sufficiently large scale. The selectivity of commercially available membranes for $\mathrm{CO}_{2} / \mathrm{H}_{2}$ is also too low.

\subsection{The NOx Challenge: Steam Supply to Combustion}

To avoid excessive NOx formation, steam must be present during combustion of the hydrogen rich $\left(\mathrm{N}_{2}\right.$-containing) fuel. The steam can either be supplied to a gas saturator located downstream of the $\mathrm{CO}_{2}$ removal unit or by injecting medium pressure steam into the $\mathrm{H}_{2}$-rich fuel stream. A saturator is a relatively costly piece of equipment, while the medium pressure steam reduces the power output from the steam turbine.

\subsection{Integration of Front-End with Power Plant}

Integration between front-end, i.e. the syngas production, $\mathrm{CO}$ conversion and $\mathrm{CO}_{2}$ removal, and power plant station is a critical success factor when precombustion schemes are compared to post-combustion schemes.

\subsection{Process Air}

In most cases, air for the reforming process will be extracted from the air compressor driven by the gas turbine. Additional air will then be compressed to the reforming pressure using a separate air compressor.

\subsection{Heat Integration}

Process steam for the reformer unit is generally produced in the heat recovery steam generation (HRSG) unit. In addition, the HRSG unit can be used to pre-heat a number of front-end process streams, such as natural gas and process air. In case extensive heat integration with the front-end is applied, firing in the exhaust gas may be required.

\subsection{Gas Turbine}

Operating a gas turbine on high hydrogen fuel mix is an area that requires special consideration. From IGCC operation gas turbines running on fuels with low heat content (low BTUfuels) are already established. General Electric (GE) has published references in which some gas turbines were operating on fuels with up to $60 \%$ hydrogen and the GE Frame 9 was selected as preferred gas turbine solution. Even though a significant number of $G E$ references existed experience with hydrogen/nitrogen mixture was an unknown area and a test program financed by Norsk Hydro at GE's test facilities was launched. The results are reported by Andenaes and Battista (2000) and Todd and Batista (2000).

The main objective of the test program was to verify the following:

- Evaluate operability and emission of the GE multi-nozzle combustor burning hydrogen-rich fuels.

- Evaluate component metal temperature throughout the load range.

- Determine sensitivity of major performance parameters to variations in the hydrogen content.

One of the most important parameters that were addressed in the test program was NOx formation. $\mathrm{NO}_{\mathrm{x}}$ emissions below 10 ppmvd at $15 \% \mathrm{O}_{2}$ were found to be achievable.

\section{DEVELOPMENT OPTIONS}

Extensive research is ongoing worldwide to bring down the costs of the PrCDC approach. The ideas span from work on single components to redesign of the whole decarbonisation process. The emphasis on different research paths and the choice of new technology will depend on individual applications and overall strategies for technology adaption. The purpose of this chapter is to give a flavour of development options, without making any recommendations.

\subsection{Integrated Reforming Combined Cycle}

The Integrated Reforming Combined Cycle (IRCC), also called Hydrokraft, is based on known components from syngas and ammonia production. The main blocks are:

- Autothermal Reforming (ATR) where natural gas is converted by use of air into a mixture of hydrogen, $\mathrm{CO}$ and $\mathrm{CO}_{2}$. 
- CO can further be converted into hydrogen in order to improve the hydrogen production and overall efficiency. This conversion is accomplished in the $\mathrm{CO}$ reactors, and the reaction is called water-gas-shift.

- $\mathrm{CO}_{2}$ is removed from the hydrogen mixture by absorption similar to the postcombustion process. The advantage however, is that this is done at much higher pressure than postcombustion $\mathrm{CO}_{2}$ removal.

- Finally, the hydrogen/nitrogen fuel mixture is fired in the gas turbine resulting in a fluegas with a very low content of $\mathrm{CO}_{2}$.

The process is illustrated in Figure 4.

\subsection{Membranes}

The major advantages of hydrogen membrane technologies are:

- Smaller equipment by combining reaction and separation in a single unit.

- Above equilibrium conversion due to selective removal of hydrogen product from reactor.

- Reduced compression cost due to production of $\mathrm{CO}_{2}$ at elevated pressure.

Research on membrane technology has focused on applications that combine chemical reaction and hydrogen separation in a single step. Two fundamentally different approaches can be envisaged:

- A single-step process for producing a hydrogen rich fuel stream and a separate $\mathrm{CO}_{2}$ stream. Such a system is generally referred to as hydrogen membrane reformer.
- A two-step approach using conventional technology such as autothermal reforming, partial oxidation or steam methane reforming to produce synthesis gas as a first step, followed by a shift section downstream of the reformer and a physical and/or chemical $\mathrm{CO}_{2}$ removal system. Membrane based systems use technology that converts the remaining $\mathrm{CO}$ in the syngas and simultaneously separates the product gases hydrogen and $\mathrm{CO}_{2}$. Such systems are generally referred to as Membrane Water Gas Shift (MWGS) Reactors.

Membrane technology has a high potential, which must be balanced against the probability of success or the risk elements associated with the technologies. This is crucial when setting up a balanced technology development portfolio. Major challenges related to membrane technologies are:

- Membrane manufacturing costs and reliability.

- Membrane long-term stability and performance.

The $\mathrm{CO}_{2}$ Capture Project (CCP) has performed a thorough study on membranes for use in PrCDC (Thomas (ed.), 2004). The membranes studies were divided into four sub-projects as listed below:

- Sulphur tolerant membrane study;

- Hydrogen Membrane Reformer;

- Hydrogen Membrane Reactor;

- Precombustion membrane reactor study.

The dominant position of membrane studies in CCP was the consequence of the very promising results achieved by the hydrogen membrane technologies in analysis work performed during 2000 and 2001, where the hydrogen membrane technologies were identified to have the best potential to achieve cost reductions.

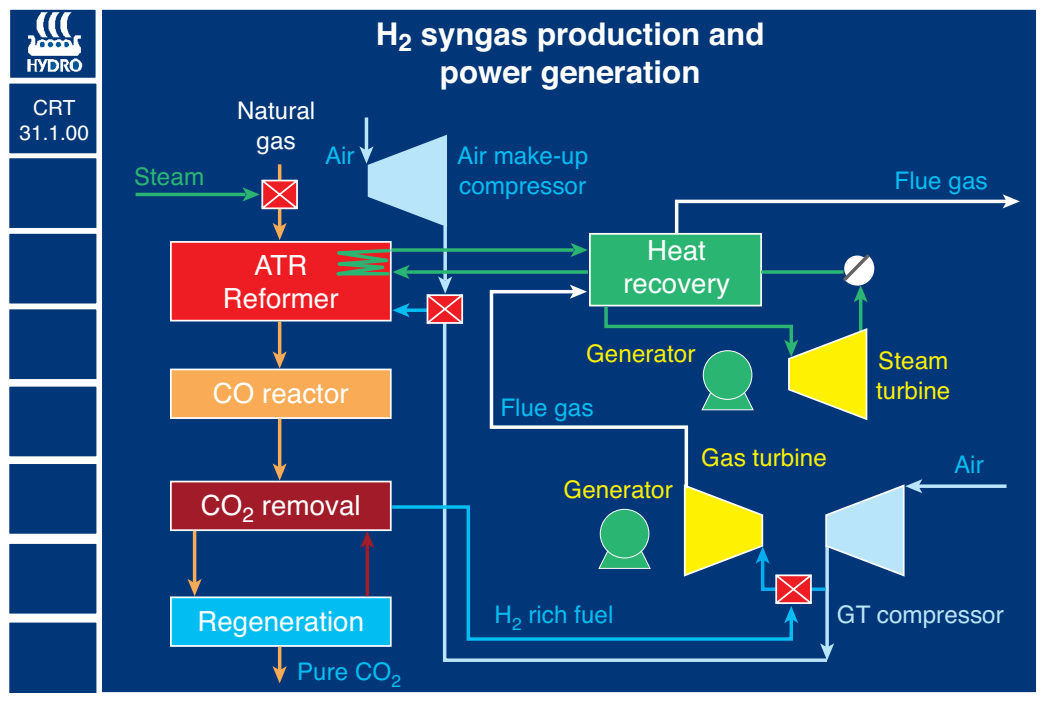

Figure 4

The IRCC process. 
The membrane water gas shift system was considered by $\mathrm{CCP}$ to be a lower risk option than a membrane reformer system for different reasons:

- Water-gas-shift reaction operates at $350-450^{\circ} \mathrm{C}$ whereas the ceramic membrane reformers operate at very high temperatures, i.e. $800-1000^{\circ} \mathrm{C}$.

- The membrane water gas shift system can be developed without integrating the reaction and membrane. This simplifies the system compared to membrane reformer system, in which reactor and membrane is fully integrated.

- Development of a sulphur tolerant membrane was not successful and it is questionable if the development of a sulphur tolerant membrane can be obtained.

CCP ranked the various membrane technologies as follows, in order of increasing risk:

- sweet syngas non-integrated hydrogen membrane;

- sweet syngas integrated water-gas-shift reactor and hydrogen membrane;

- integrated ceramic membrane reformer system;

- sulphur tolerant hydrogen membrane.

\subsection{Generation of $\mathrm{H}_{2}$ Fuels}

An approach based on $\mathrm{CaO}$ as an oxidant to drive the reforming reaction is described in Thomas (2004). The results showed that for combined cycle gas turbines the technology could not obtain satisfactory energy efficiency, only $40 \%$ (LHV). For the heater and boilers option, the efficiency was estimated to be approximately $82 \%$ (LHV), if electricity credit was included. Finally, $90 \% \mathrm{CO}_{2}$ capture efficiency could be obtained for both applications. The approach is based on converting $\mathrm{CaO}$ to $\mathrm{CaCO}_{3}$ and calcined back to $\mathrm{CaO}$, which is recycled back to the reforming reactor. A key challenge is, therefore, to develop a reactor system that recycle solid materials efficiently. This risk associated to the development of the technology may be considered high and fundamental studies and lab testing must be conducted before pilot testing can be realized.

\subsection{Production of Hydrogen Fuel by Sorbent Enhanced Water Gas Shift (SEWGS) Reaction}

The SEWGS process combines the water gas shift reaction with high temperature $\mathrm{CO}_{2}$ removal via a solid adsorbent to simultaneously react $\mathrm{CO}$ to low levels and remove $\mathrm{CO}_{2}$.

$$
\mathrm{CO}+\mathrm{H}_{2} \mathrm{O} \Leftrightarrow \mathrm{CO}_{2}+\mathrm{H}_{2}
$$

A high-pressure, high-temperature $\mathrm{H}_{2}$ product stream is produced which is used to generate power in a gas turbine. Waste heat can be converted to power via steam turbines. The technology comprises a high temperature cyclic pressure swing adsorption (PSA) process for removal of $\mathrm{CO}_{2}$ from a reactor in which the water-gas shift conversion of $\mathrm{CO}$ is simultaneously occurring.

Work performed by Air Products and Chemicals (APCI) as part of CCP identified adsorbents which are capable of removing $\mathrm{CO}_{2}$ at high temperatures. Experimental proof of concept test runs were undertaken to confirm the feasibility of this approach (Thomas 2004).

The following adsorbent types were evaluated:

- promoted hydrotalcites (HTC) with a range of promotors (7 types);

- double salts-combinations of metal oxides and carbonates (20 combinations);

- metal oxides as pure materials or supported on alumina.

- Toshiba lithium orthosilicate based material.

The key findings were that in the rapid cyclic service of a SEWGS system, the hydrotalcites have the highest $\mathrm{CO}_{2}$ capacity of the materials tested. Processes incorporating this system were designed for decarbonisation of gas fuels for gas turbines, and evaluated for a $400 \mathrm{MW}$ combined cycle gas turbine and smaller distributed gas turbines. The systems showed high efficiencies due to the high temperature of the product fuel. Low NOX emissions (below $25 \mathrm{ppm}$ ) appeared also to be achievable.

\section{REFERENCES}

Andenaes, S. and R.A. Battista (2000) Integrated Hydrogen Fueled Gas Turbines for Low $\mathrm{CO}_{2}$ Emission Power Plant. EFI Green technologies, January 31.

Brun, K. and Jones, R. (2001) Economic Viability and Experience of IGCC from a Gas Turbine Manufacturers Perspective.Presented at ASME Turbo Expo, New Orleans, USA, June.

Domenichini, R. (2003) Potential for Improvement in Gasification Combined Cycle Power Generation with $\mathrm{CO}_{2}$ Capture. IEA GHG R\&D Programme, Report No. PH4/19, May.

Thomas, D. (ed.) (2005) Carbon Dioxide Capture for Storage in Deep Geologic Formations - Results from the $\mathrm{CO}_{2}$ Capture Project, 1: Capture and Separation of Carbon Dioxide from Combustion Sources, Elsevier.

Todd, D.M, and Battista, R.A. (2000) Demonstrated Applicability of Hydrogen Fuel for Gas Turbines, presented at Gasification 4 the Future, 11-13 April, Amsterdam.

Final manuscript received in May 2005 